\title{
Haemodynamics of the circle of Willis and the leptomeningeal anastomoses: an electromagnetic flowmeter study of intracranial arterial occlusion in the monkey
}

\author{
SUSUMU ISHIKAWA ${ }^{1}$, JYOJI HANDA ${ }^{1}$, JOHN S. MEYER, AND PETER HUBER ${ }^{1}$ \\ From the Department of Neurology, Wayne State University School of Medicine, the Detroit Receiving \\ Hospital, and the Wayne Center for Cerebrovascular Research
}

Since Thomas Willis's original description of the arterial circle at the base of the brain in 1664, many studies have been made of its function to provide collateral circulation. These include injection experiments (Kramer, 1912; McDonald and Potter, 1951); carotid and vertebral flow measurements following occlusion of the arteries in the neck (Hardesty, Roberts, Toole, and Royster, 1960; Stern, 1962; Symon, Ishikawa, Lavy, and Meyer, 1963a; Handa, Ishikawa, Huber, and Meyer, 1965); arterial pressure measurements (Bakay and Sweet, 1952; Woodhall, Odom, Bloor, and Golden, 1952); cerebral angiography (Tönnis and Schiefer, 1959); and experiments using hydrodynamic models (Kramer, 1912; Rogers, 1947; Avman and Bering, 1961; Murray, 1964). The qualitative importance of the leptomeningeal anastomoses as a supplemental collateral circulation beyond the circle of Willis has also been demonstrated in experimental animals and in man (Meyer, Fang, and Denny-Brown, 1954; Rosegay and Welch, 1954; Welch, Stephens, Huber, and Ingersoll, 1955; Symon, 1961 ; Symon, Ishikawa, and Meyer, 1963b).

The present study was designed to compare quantitatively the dynamic functions of the circle of Willis and leptomeningeal anastomoses in the monkey by application of electromagnetic flowmeters to the carotid and vertebral arteries while temporarily occluding their intracranial branches.

\section{MATERIALS AND METHODS}

Eighteen monkeys of either sex weighing between 3 and $6.5 \mathrm{~kg}$. were used. The majority were Macacus speciosa, but four African green, three Cynomologous monkeys, and one Macacus rhesus were included. Results were not significantly different between species. Anaesthesia was induced with intravenous pentobarbital sodium, initially $30 \mathrm{mg} . / \mathrm{kg}$., which was supplemented as necessary. A

${ }^{1}$ Fellows of the Michigan Heart Association. Dr. Ishikawa's present address is Department of Neurosurgery, Kyoto University Medical School, Kyoto, Japan. tracheal cannula was inserted and the endotracheal $\mathrm{CO}_{2}$ concentration was monitored with a Beckman infrared gas analyser. Systemic blood pressure was recorded by a Statham strain gauge and a catheter threaded into the abdominal aorta via the femoral artery. The mean arterial pressure was maintained between 125 and $65 \mathrm{~mm}$. $\mathrm{Hg}$, and the systolic pressure over $105 \mathrm{~mm}$. $\mathrm{Hg}$. Another catheter was put in the femoral vein for injection of drugs. The common, internal, and the external carotid arteries were exposed bilaterally. The carotid sinuses were denervated on both sides. In eight monkeys the middle two-thirds of the clavicle was removed on the right side, and in several monkeys on the left. The sternum was resected from the suprasternal notch to the level of the second intercostal space. The vertebral artery was extensively exposed on the side of clavicular resection.

The zygomatic arch and temporal muscles were removed on the right side in 15 animals and on the left in three, and an extensive craniectomy was performed in the temporofrontal region. The circle of Willis was approached by the overhanging head method. The intracranial portion of the internal carotid artery, the proximal portions of the anterior and middle cerebral arteries, and the posterior communicating artery were freed from their arachnoid coverings. A light spring-clamp was used for temporary occlusion of the intracranial artery.

Because of technical difficulties in the application of electromagnetic flow-probes directly on the internal carotid artery, a flow-probe was put on each common carotid artery and the external carotid artery was ligated. Both external jugular veins were ligated. Integrated blood flow in each carotid artery was measured with a $2 \mathrm{~mm}$. lumen-diameter probe and Metroflo flowmeter (series 6000, Avionics Research Corporation, Los Angeles); the integrated flow in the vertebral artery was measured with a $1 \mathrm{~mm}$. probe and Microflo flowmeter (model FM 6, Medicon Division of Statham Instruments, Inc., Los Angeles). Technical problems occurring with the simultaneous use of two to three flowmeters, their calibration in vitro, and the determination of a zero reference in vivo have been described in previous papers (Symon et al., 1963a; Meyer, Ishikawa, and Lee, 1964). Ink records of all parameters were made with a Grass model 5 polygraph. 


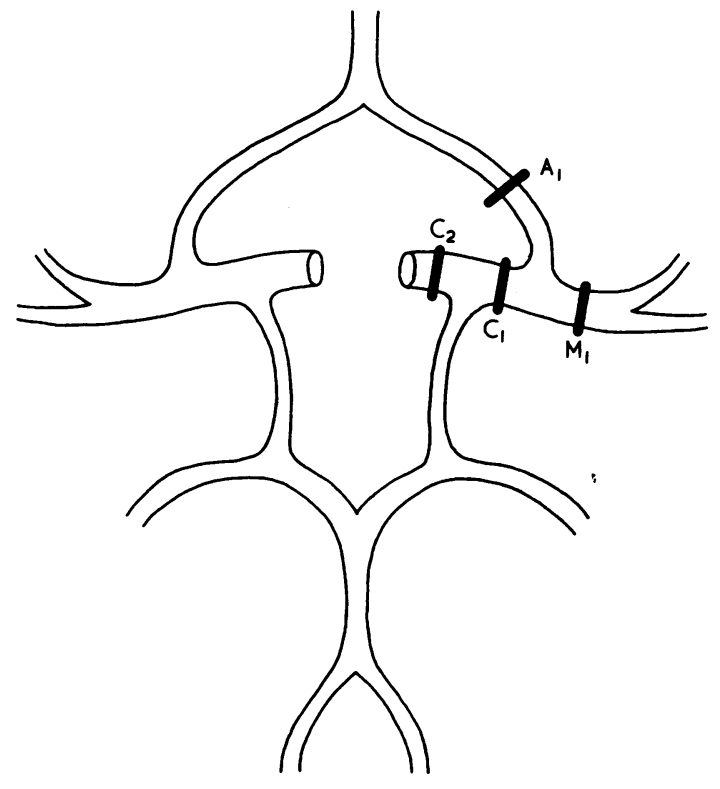

FIG. 1. Positions of occlusion of intracranial arteries.

After each experiment, the brain was removed and weighed and the circle of Willis was examined with a magnifying glass. As is well known, in the monkey the two anterior cerebral arteries fuse at or near their entrance into the interhemispherical fissure to form a single common pericallosal artery. In one monkey (no. 15), the left anterior cerebral artery was absent. No abnormalities in the circle of Willis were found in other animals. For brevity and convenience of nomenclature, the intracranial portion of the internal carotid artery proximal to the posterior communicating artery will be abbreviated to $C_{2}$ and the portion of the carotid distal to the posterior communicating artery will be called $\mathrm{C}_{1}$ (Fig. 1). The proximal portion of the anterior and middle cerebral arteries will be called $A_{1}$ and $M_{1}$ respectively. Since the collateral circulation possible via the circle of Willis and leptomeningeal vessels is influenced greatly by the anatomical site of occlusion, the designated site of occlusion is of the utmost importance.

\section{RESULTS}

EFFECT OF OCCLUSION OF THE INTERNAL CAROTID ARTERY AT $\mathrm{C}_{2}$ Occlusion of the internal carotid artery at $\mathrm{C}_{2}$, which permitted collateral flow from the posterior communicating artery, resulted in a decrease in flow through the ipsilateral carotid, which varied from $41 \cdot 1$ to $71.5 \%$ of preocclusion level, the average being $55 \cdot 8 \%$ (S.D. $= \pm 8 \cdot 8$ ). An increase was observed in contralateral carotid and ipsilateral vertebral flow, which ranged from $9 \cdot 1$ to
TABLE I

EFFECT OF $C_{2}$ OCCLUSION ON FLOW IN THE IPSILATERAL INTERNAL CAROTID, CONTRALATERAL INTERNAL CAROTID, AND IPSILATERAL VERTEBRAL ARTERIES

Percentage Change in Flow in

\begin{tabular}{|c|c|c|c|}
\hline \multirow[b]{2}{*}{$\begin{array}{l}\text { Animal } \\
\text { Nos. }\end{array}$} & \multicolumn{3}{|c|}{ Percentage Change in Flow in } \\
\hline & $\begin{array}{l}\text { Ipsilateral } \\
\text { Internal } \\
\text { Carotid }\end{array}$ & $\begin{array}{l}\text { Contralateral } \\
\text { Internal } \\
\text { Carotid }\end{array}$ & $\begin{array}{l}\text { Ipsilateral } \\
\text { Vertebral }\end{array}$ \\
\hline 3 & $-55 \cdot 0$ & +26.9 & $* * * *$ \\
\hline 4 & $-52 \cdot 7$ & $\begin{array}{r}9 \cdot 1 \\
+9 \cdot 1\end{array}$ & $* * * *$ \\
\hline 5 & $-44 \cdot 1$ & +22.6 & $* * * *$ \\
\hline 6 & $-58 \cdot 4$ & $+35 \cdot 1$ & $* * * *$ \\
\hline 7 & $-48 \cdot 1$ & $+24 \cdot 5$ & +8.7 \\
\hline 8 & $-46 \cdot 0$ & $* * * *$ & +16.7 \\
\hline 10 & $-64 \cdot 1$ & +23.9 & $* * * *$ \\
\hline 11 & $-55 \cdot 0$ & $+24 \cdot 6$ & $+36 \cdot 2$ \\
\hline 13 & $-70 \cdot 0$ & +21.9 & $+19 \cdot 4$ \\
\hline 14 & $-57 \cdot 8$ & $+22 \cdot 0$ & +11.8 \\
\hline 16 & $-55 \cdot 1$ & $+10 \cdot 8$ & +10.5 \\
\hline 17 & $-71 \cdot 5$ & $+24 \cdot 8$ & $+26 \cdot 1$ \\
\hline 19 & $-62 \cdot 4$ & $+13 \cdot 2$ & $* * * *$ \\
\hline 20 & $-41 \cdot 1$ & $+15 \cdot 7$ & $+30 \cdot 0$ \\
\hline Mean & $-55 \cdot 8$ & $\pm 19 \cdot 7$ & +19.9 \\
\hline S.D. & $\pm \mathbf{8 . 8}$ & $\pm 7 \cdot 1$ & $\pm 9 \cdot 3$ \\
\hline
\end{tabular}

****No flow measurements were made.

$35 \cdot 1 \%$, the average being $19 \cdot 7 \%$ (S.D. $= \pm 7 \cdot 1$ ), and from 8.7 to $36.2 \%$, mean value being $19.9 \%$ (S.D. $= \pm 9 \cdot 3)$ respectively. A typical example is illustrated in Figures 2A, 3A, and 10A. Percentage alterations in flow are summarized in Table $\mathrm{I}$.

In one monkey (no. 15) whose left anterior cerebral artery was absent, a compensatory increase in the contralateral carotid flow was no more than $4.3 \%$ and an increase in the ipsilateral vertebral flow reached $27 \cdot 3 \%$, although a reduction in the ipsilateral internal carotid flow was $42.9 \%$. The data from this animal were excluded from the calculation of mean values, because of the anomaly of the circle of Willis found at necropsy. However, the importance of such anomalies (which are present in about $20 \%$ of human cases) in reducing the effective collateral circulation is emphasized.

The collateral adjustment in flow in each artery was immediate, and scarcely changed thereafter during the period of occlusion (1 minute) unless there was significant fluctuation in systemic blood pressure. There was an exception in one monkey (no. 11), in which the compensatory rise of contralateral carotid flow continued to increase during $\mathrm{C}_{2}$ occlusion $(9.7 \%)$ despite a stable blood pressure (Fig. 2).

After release of the occlusion, flow returned promptly to the pre-occlusion level without showing any overswing (reactive hyperaemia) except for two observations in two animals (nos. 6 and 8), in which flow slowly came back to steady state levels during the ensuing one to two minutes (Fig. 3A).

EFFECT OF OCCLUSION OF THE INTERNAL CAROTID ARTERY AT $C_{1}$ The reduction of ipsilateral carotid 
A
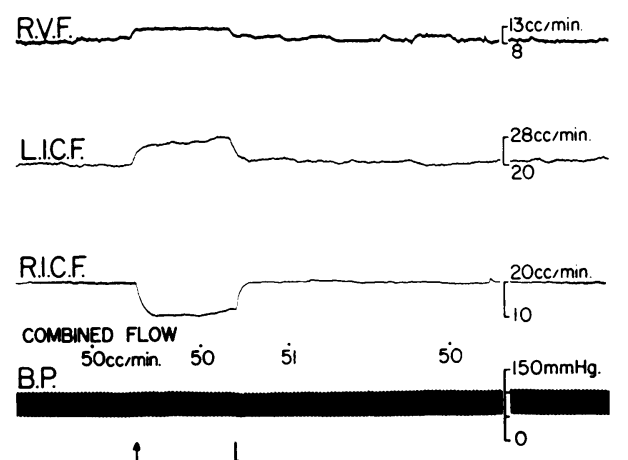
R.C.Occl. Rel.

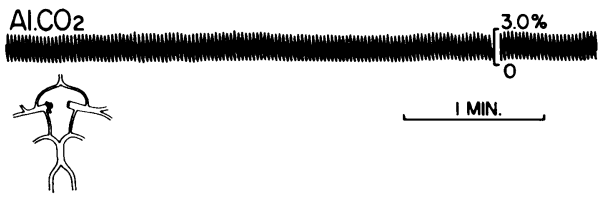

B
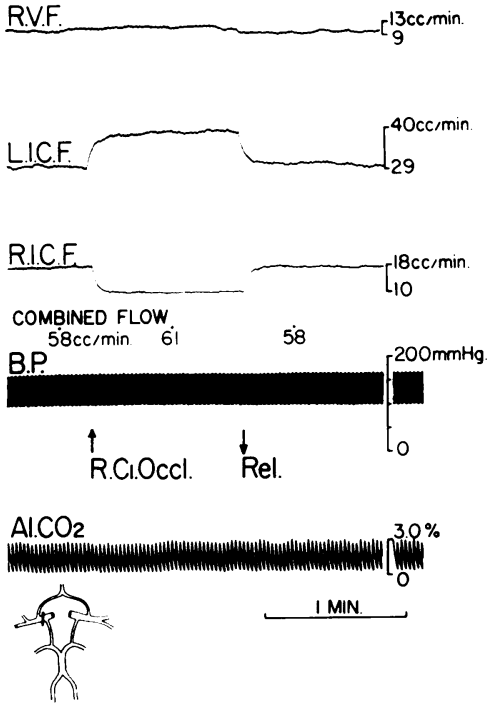

FIG. 2. Records $A$ and $B$ are from the same monkey (no. 11).

A. Effect of right $C_{2}$ occlusion on flow in the right vertebral (R.V ${ }^{2}$.F.), the left (L.I.C.F.), and the right (R.I.C.F.) internal carotid arteries. B.P. and Al.CO $\mathrm{CO}_{2}$ are systemic blood pressure and tracheal carbon dioxide concentration respectively. Calibrations are shown on the record. Diagram shows the position of arterial occlusion.

$B$. Effect of right $C_{1}$ occlusion on flow in the right vertebral and the left and right internal carotid arteries.
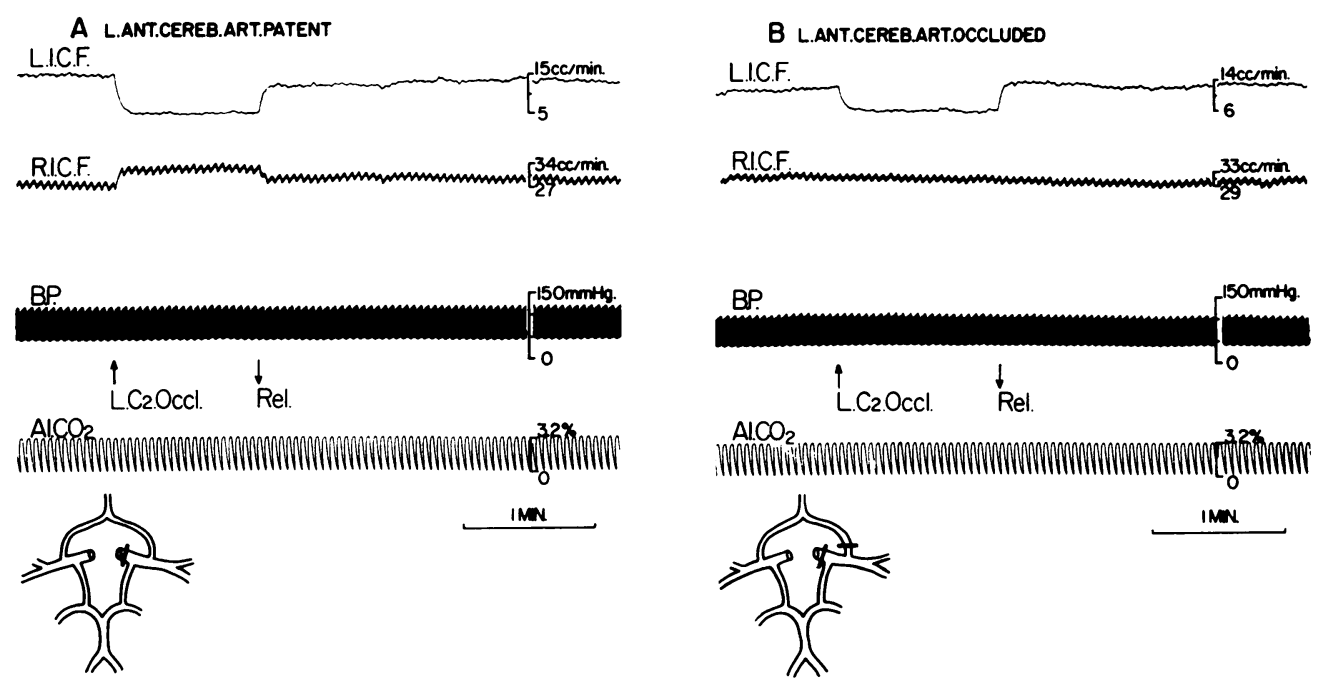

FIG. 3. Records $A$ and $B$ are from the same animal (no. 6).

A. Effect of left $C_{2}$ occlusion on flow in the bilateral internal carotid arteries.

$B$. The left anterior cerebral artery had been occluded before $C_{2}$ occlusion. A compensatory increase in the right internal carotid flow was completely abolished. Reactive hyperaemia is seen in left internal carotid flow on release of $C_{2}$ occlusion. 
flow following the occlusion at $\mathrm{C}_{1}$, which did not permit collateral flow via the posterior communicating artery, varied from 23.2 to $60.8 \%$ of initial value, average being $44.5 \%$ (S.D. $= \pm 10 \cdot 4)$. Contralateral carotid flow immediately increased by 11.9 to $35.9 \%$, mean increase being $23.6 \%$ (S.D. $= \pm 6.0$ ). Flow in the ipsilateral vertebral artery showed an increase of $1.2 \%$ in one animal, no change in three animals, and a slight decrease from 0.5 to $6.4 \%$ in four animals, mean value for all eight monkeys being $2 \cdot 1 \%$ reduction $($ S.D. $= \pm 2 \cdot 8)$ (Table II). A typical example is illustrated in Figure $2 \mathrm{~B}$.

\section{TABLE II}

EFFECT OF $C_{1}$ OCCLUSION OF FLOW IN THE BILATERAL INTERNAL CAROTID AND IPSILATERAL VERTEBRAL ARTERIES

\begin{tabular}{|c|c|c|c|}
\hline \multirow[b]{2}{*}{$\begin{array}{l}\text { Animal } \\
\text { Nos. }\end{array}$} & \multicolumn{3}{|c|}{ Percentage Change in Flow in } \\
\hline & $\begin{array}{l}\text { Ipsilateral } \\
\text { Internal } \\
\text { Carotid }\end{array}$ & $\begin{array}{l}\text { Contralateral } \\
\text { Internal } \\
\text { Carotid }\end{array}$ & $\begin{array}{l}\text { Ipsilateral } \\
\text { Vertebral }\end{array}$ \\
\hline 2 & $-51 \cdot 6$ & +35.9 & $* * * *$ \\
\hline 3 & $-47 \cdot 3$ & $+27 \cdot 4$ & $* * * *$ \\
\hline 4 & $-41 \cdot 8$ & +11.9 & $* * * *$ \\
\hline 5 & $-53 \cdot 3$ & +18.9 & $* * * *$ \\
\hline 6 & $-47 \cdot 0$ & $+14 \cdot 1$ & $* * * *$ \\
\hline 7 & $-49 \cdot 8$ & $* * * *$ & $+1 \cdot 2$ \\
\hline 8 & $-23 \cdot 2$ & $* * * *$ & -0.5 \\
\hline 10 & $-39 \cdot 1$ & $+27 \cdot 3$ & $* * * *$ \\
\hline 11 & $-32 \cdot 4$ & $+20 \cdot 3$ & - \\
\hline 12 & $-33 \cdot 7$ & +21.6 & $* * * *$ \\
\hline 13 & $-46 \cdot 6$ & $+31 \cdot 3$ & -5.6 \\
\hline 14 & $-33 \cdot 7$ & $+30 \cdot 0$ & - \\
\hline 16 & $-55 \cdot 3$ & +20.5 & - \\
\hline 17 & $-36 \cdot 1$ & +26.8 & -5.8 \\
\hline 19 & -60.5 & +25.9 & -6.4 \\
\hline 20 & $-60 \cdot 8$ & +19.5 & $* * * *$ \\
\hline Mean & -44.5 & +23.6 & $-2 \cdot 1$ \\
\hline S.D. & \pm 10.4 & $=6.0$ & \pm 2.8 \\
\hline
\end{tabular}

****No flow measurements were made.

In the one monkey (no. 15), which had an incomplete circle of Willis, the compensatory increase in flow of the contralateral carotid reached only $5.6 \%$, but the reduction in the ipsilateral vertebral flow was as much as $12.3 \%$. A decrease of $25.3 \%$ was produced in flow through the ipsilateral internal carotid artery (Fig. 4). The results from this monkey were excluded from calculation of mean values because of the anomaly present.

The response in flow of each artery resulting from $\mathrm{C}_{1}$ occlusion was immediate, and in the majority, remained unchanged during the period of occlusion. However, in one monkey (no. 11), flow in the contralateral internal carotid artery showed a progressive increase over the period of $\mathrm{C}_{1}$ occlusion, reaching a maximum level $6.7 \%$ higher than the value immediately after the occlusion (Fig. 2B). In a second monkey (no. 18), the compensatory rise of contralateral internal carotid flow increased remarkably during $\mathrm{C}_{1}$ occlusion, without change in
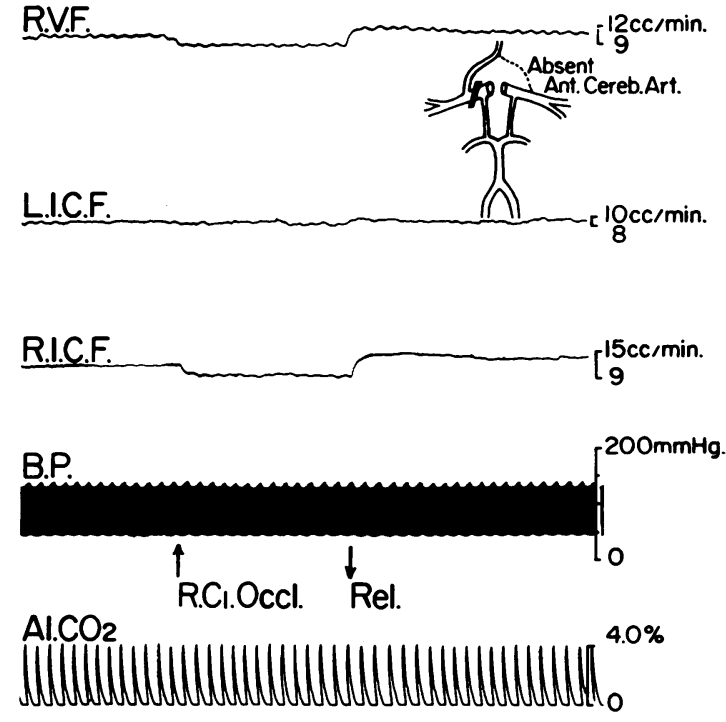

I MNN.

FIG. 4. Effect of right $C_{1}$ occlusion on flow in the right vertebral and left and right internal carotid arteries. In this monkey (no. 15), the left anterior cerebral artery was atsent. The usual response of compensatory increase in the contralateral internal carotid flow was not found.
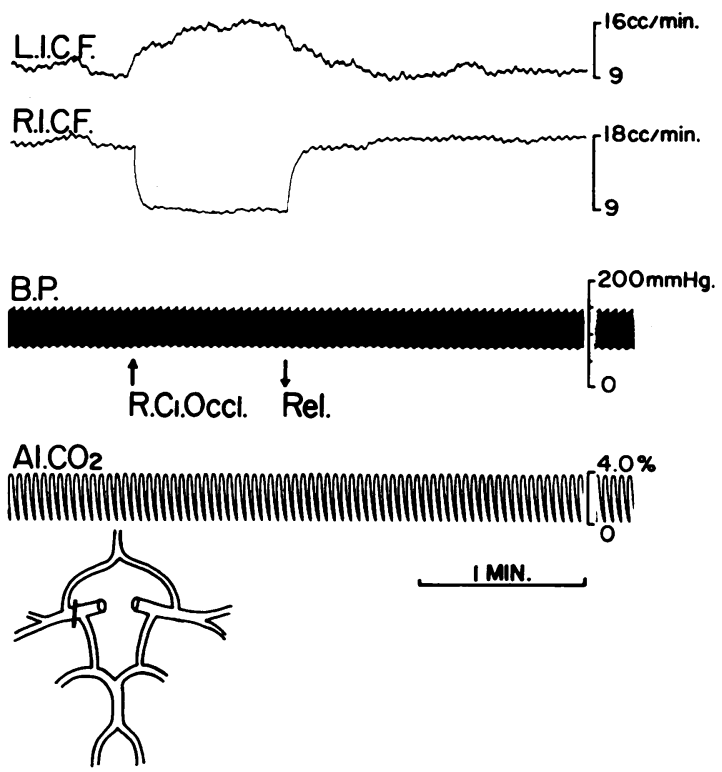

FIG. 5. Right $C_{1}$ occlusion. Response of contralateral carotid flow in the monkey (no. 18) was unusual. Left internal carotid flow increased to the level of $45.1 \%$ higher than the resting value, remained at this level for 15 seconds, then started to increase again until the maximum increase of $72 \%$ was gained. 
systemic blood pressure. The increase in contralateral carotid flow was $45.1 \%$ immediately after $\mathrm{C}_{1}$ occlusion. The flow remained at this level for the first 15 seconds, then started to rise gradually over the next 25 seconds, to reach the maximum value of $72.0 \%$ higher than the pre-occlusion level (Fig. 5). This animal was excluded from statistical analysis since the results were unusual.

In all animals except no. 18, flow in each artery returned promptly to previous levels without any hyperaemia when $C_{1}$ was released. In no. 18 , however, flow in the contralateral carotid gradually returned to the resting value.

EFFECT OF OCCLUSION OF THE ANTERIOR CEREBRAL ARTERY AT A $A_{1}$ Occlusion of the anterior cerebral artery at $A_{1}$ was followed by a decrease in flow in the ipsilateral carotid artery, ranging from 5.7 to $16.0 \%$, the mean value being $10.9 \%$ (S.D. $= \pm 2.0)$. The contralateral carotid flow showed an increase of 2.8 to $17.4 \%$, the average being $10.8 \%$ (S.D. = $\pm 4 \cdot 8$ ). A decrease in ipsilateral vertebral flow was seen in all animals, which varied from 3.8 to $13.3 \%$, the average being $8.0 \%$ (S.D. $= \pm 3.6)$ (Table III).

TABLE II I

EFFECT OF $A_{1}$ OCCLUSION ON FLOW IN BILATERAL INTERNAL CAROTID AND IPSILATERAL VERTEBRAL ARTERIES

\begin{tabular}{lccc}
\multicolumn{5}{c}{ Percentage Change in Flow in } \\
\cline { 2 - 4 } $\begin{array}{l}\text { Animal } \\
\text { Nos. }\end{array}$ & $\begin{array}{l}\text { Ipsilateral } \\
\text { Internal } \\
\text { Carotid }\end{array}$ & $\begin{array}{l}\text { Contralateral } \\
\text { Internal } \\
\text { Carotid }\end{array}$ & $\begin{array}{l}\text { Ipsilateral } \\
\text { Vertebral }\end{array}$ \\
\hline 10 & -11.0 & +7.6 & $* * * *$ \\
11 & -9.5 & +2.8 & -3.8 \\
14 & -5.7 & +9.6 & -11.1 \\
16 & -16.0 & +15.3 & -5.0 \\
17 & -11.2 & +17.4 & -6.9 \\
19 & -11.9 & +12.1 & -13.3 \\
Mean & -10.9 & +10.8 & -8.0 \\
S.D. & \pm 2.0 & \pm 4.8 & \pm 3.6 \\
$* * * *$ No study was made. & &
\end{tabular}

Figure 6 illustrates a typical example of these changes. The response of flow in each artery was prompt and remained unchanged during the occlusion, except for slight fluctuations due to blood pressure alterations. Following release of the occlusion, flow returned promptly to the original levels.

EFFECT OF OCCLUSION OF THE MIDDLE CEREBRAL ARTERY AT $M_{1}$ Occlusion of the middle cerebral artery at $M_{1}$ for one minute resulted in a prompt reduction of flow of the ipsilateral carotid artery. The decrease ranged from $15 \cdot 8$ to $39.3 \%$, the mean value being $23.8 \%$ (S.D. $= \pm 3.9$ ) of the preocclusion value. The contralateral carotid flow showed an increase in two animals of $4.4 \%$ and
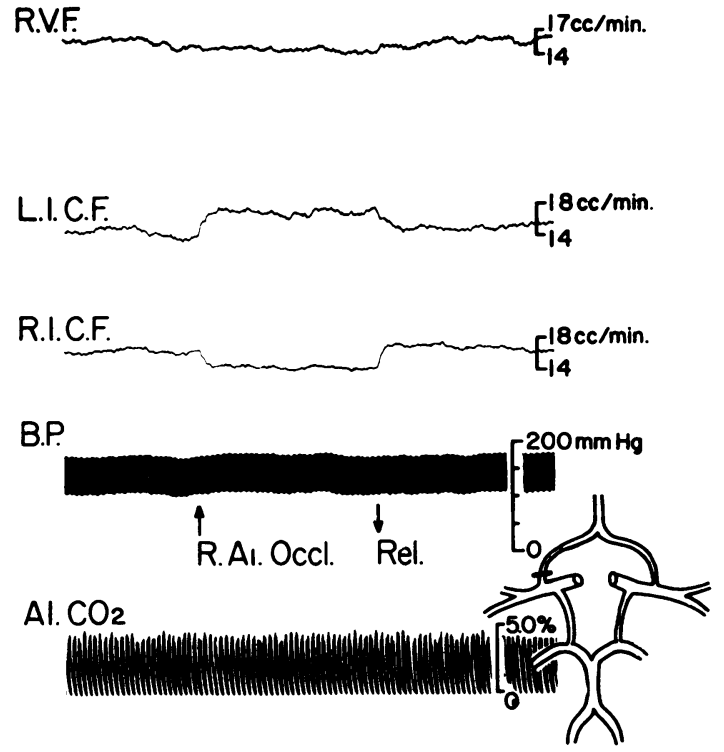

FIG. 6. Effect of right $A_{1}$ occlusion on flow in the right vertebral, and the left and right internal carotid arteries. Slight but clear decrease is noted in right vertebral flow.

$0.6 \%$ respectively and a decrease in 11 monkeys舫 which varied from 1.4 to $9.8 \%$. The mean change ino flow of the contralateral carotid flow in all 13 animals amounted to a reduction of $3.6 \%$ (S.D. $\pm 2.8)$. An increase in flow in the ipsilateral vertebral artery of $0.5 \%$ was observed in one monkey, and 20 decrease in six animals, which varied from $1 \cdot 1$ to $9.7 \%$ of the pre-occlusion value. The mean value for these eight animals was a $3.8 \%$ reduction (S.D. = $\pm 3 \cdot 2$ ) in flow of the ipsilateral vertebral (Table IV). Examples are illustrated in Figures 7A and 8A.

The response in flow of each artery following $M_{1}$ occlusion was prompt, and usually did not change perceptively over the whole period of occlusion. In one monkey (no. 11), however, contralateral internal carotid flow increased gradually during $M_{1}$ occlusion and returned to the original level within one minute of release (Fig. 7A). In another monkey (no. 18), which was not included in the calculation of the mean values, contralateral carotid flow showed an increase of $11.8 \%$ immediately after $M_{1}$ occlusion and remained at this level for approximately 15 seconds, then increased gradually over the next 15 seconds to reach a maximum level of $19.1 \%$ higher than the pre-occlusion level (Fig. 8A). This progressive increase, however, was almost completely abolished, when systemic blood pressure was decreased to $60 / 20 \mathrm{~mm}$. $\mathrm{Hg}$ by bleeding (Fig. 8B).

After release of $M_{1}$ occlusion, a transitory period of overshoot was found in the ipsilateral carotid 


\section{A R.ANTCEREBART.PATENT}
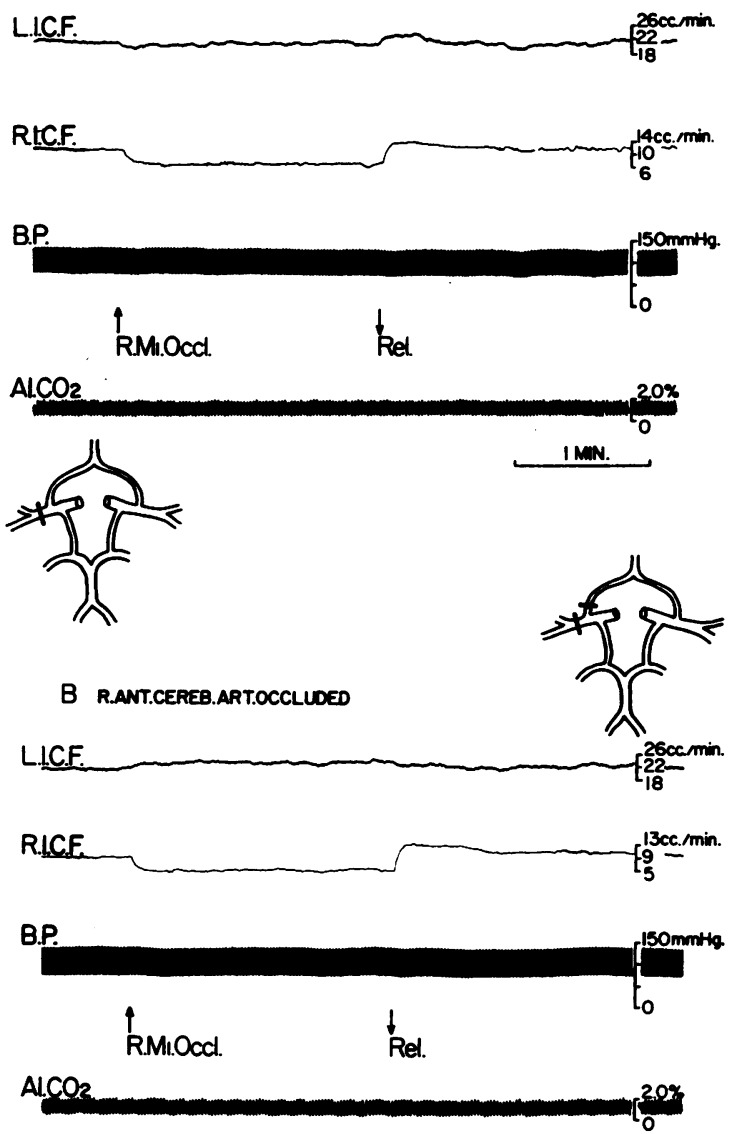

FIG. 7 .

A.
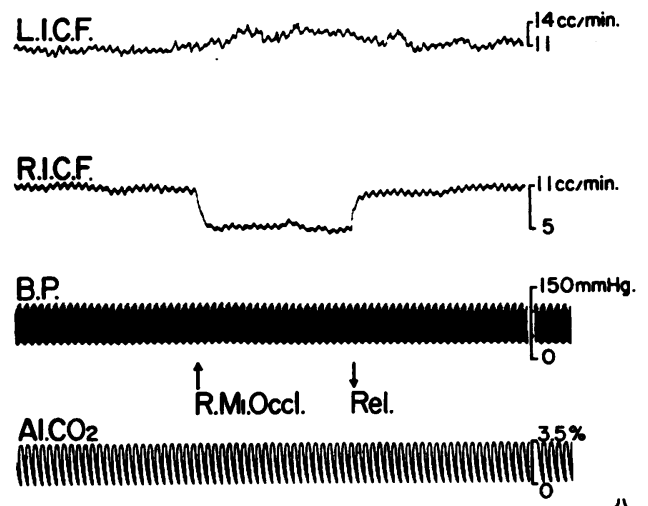

FIG. 8.

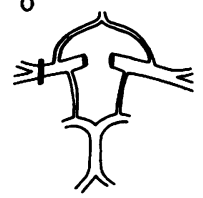

FIG. 7. Records $A$ and $B$ are from the same monkey (no. 11).

A Effect of right $M_{1}$ occlusion on the bilateral internal carotid flow. In this monkey, left internal carotid flow decreased after $M_{1}$ occlusion, then increased gradually until it reached the pre-occlusion level. After release, reactive hyperaemia was noted on both sides.

$B$ The right anterior cerebral artery has been occluded before $M_{1}$ occlusion. Left internal carotid flow showed an increase instead of a decrease seen in Figure $6 A$.

FIG. 8. Effect of right $M_{1}$ occlusion on bilateral internal carotid flow. From the same monkey (no. 18) as in Figure 4. $A$ Under normal blood pressure, left internal carotid flow showed an increase of $11.8 \%$ after right $M_{1}$ occlusion, remained at this level for 15 seconds and then started to rise again until maximum flow was reached. Transitory overshoot was not observed in right internal carotid flow following release of $M_{1}$ occlusion.

$B$ Blood pressure was reduced to the level of $60 / 20 \mathrm{~mm} . \mathrm{Hg}$. $A$ compensatory increase in contralateral internal carotid flow was nearly completely abolished. After release, reactive hyperaemia was noted in right internal carotid flow.

B.
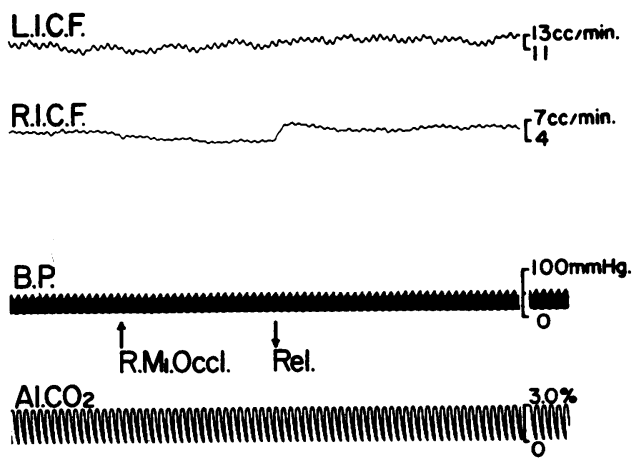
TABLE IV

EFFECT OF $M_{1}$ OCCLUSION ON FLOW IN THE BILATERAL INTERNAL CAROTID AND IPSILATERAL VERTEBRAL ARTERIES

\begin{tabular}{|c|c|c|c|}
\hline \multirow[b]{2}{*}{$\begin{array}{l}\text { Animal } \\
\text { Nos. }\end{array}$} & \multicolumn{3}{|c|}{ Percentage Changes in Flow } \\
\hline & $\begin{array}{l}\text { Ipsilateral } \\
\text { Internal } \\
\text { Carotid }\end{array}$ & $\begin{array}{l}\text { Contralateral } \\
\text { Internal } \\
\text { Carotid }\end{array}$ & $\begin{array}{l}\text { Ipsilateral } \\
\text { Vertebral }\end{array}$ \\
\hline 3 & $-27 \cdot 0$ & $+4 \cdot 4$ & $* * * *$ \\
\hline 4 & $-23 \cdot 3$ & -8.4 & $* * * *$ \\
\hline 5 & $-23 \cdot 5$ & $-4 \cdot 0$ & $* * * *$ \\
\hline 6 & -25.9 & +0.6 & $* * * *$ \\
\hline 7 & $-39 \cdot 3$ & $* * * *$ & +0.5 \\
\hline 8 & $-18 \cdot 1$ & $* * * *$ & -6.5 \\
\hline 10 & -20.9 & $-4 \cdot 7$ & $* * * *$ \\
\hline 11 & $-27 \cdot 5$ & -1.4 & - \\
\hline 12 & $-21 \cdot 6$ & -3.6 & $* * * *$ \\
\hline 13 & -19.9 & $-3 \cdot 8$ & $-3 \cdot 3$ \\
\hline 14 & $-18 \cdot 7$ & $-2 \cdot 9$ & $-1 \cdot 1$ \\
\hline 16 & $-22 \cdot 5$ & $-8 \cdot 5$ & -3.3 \\
\hline 17 & -15.8 & $-3 \cdot 1$ & -6.6 \\
\hline 19 & -28.0 & $-2 \cdot 2$ & -9.7 \\
\hline 20 & $-24 \cdot 6$ & -9.8 & $* * * *$ \\
\hline Mean & -23.8 & $-3 \cdot 6$ & $-3 \cdot 8$ \\
\hline S.D. & \pm 3.9 & $\pm 2 \cdot 8$ & $\pm 3 \cdot 2$ \\
\hline
\end{tabular}

****No studies were made.

flow of all animals except for one (no. 18), which varied from $7 \cdot 4$ to $26 \cdot 8 \%$, the average being $15.6 \%$ (S.D. $= \pm 4.8)$ of the pre-occlusion level and lasted between 45 seconds and two minutes in cases of occlusion for one minute. In one animal (no. 18), a reactive hyperaemia was not observed (Fig. 8A), although it appeared when hypotension was induced (Fig. 8B).

Reactive hyperaemia was also observed in the flow of the contralateral carotid artery of one monkey (no. 11), following two minutes of occlusion at $M_{1}$. The overswing was $7.1 \%$ at its highest point and continued for about 10 seconds (Fig. 7A). In another animal (no. 17), a reactive hyperaemia of $7 \cdot 1 \%$ and of one minute's duration was produced in the ipsilateral vertebral flow by occlusion at $M_{1}$ for one minute (Fig. 9).

RELATIONSHIP BETWEEN DURATION OF MIDDLE CEREBRAL OCCLUSION AND REACTIVE HYPERAEMIA In tWo animals (nos. 13 and 17), any relationship between the duration of occlusion at $M_{1}$ and the magnitude of the reactive hyperaemia in the ipsilateral internal carotid flow was examined. The middle cerebral artery was occluded for 15 seconds, one minute, and three minutes in each animal. In one monkey (no. 17), the hyperaemia after 15 seconds, one minute. and three minutes' occlusion was $7.4 \%, 15.9 \%$, and $19.3 \%$ respectively, and the period of hyperaemia lasted for 47 seconds, two and a half minutes, and four and a half minutes respectively (Figs. 9A, 9B, and $9 \mathrm{C}$ ). In the other animal (no. 13), these values were $3.0 \%, 13.8 \%$, and $17.1 \%$, and 30 seconds, one and one third minutes, and four and a half minutes respectively. Systemic blood pressure remained constant during these procedures.

INFLUENCE OF OCCLUSION AT $A_{1}$ ON $\mathrm{C}_{2}$ OCCLUSION The effect of $\mathrm{C}_{2}$ occlusion was examined in two monkeys (nos. 6 and 20) following the previous occlusion of the ipsilateral anterior cerebral artery at $A_{1}$. The compensatory increase in flow of the contralateral carotid was completely abolished in one monkey (no. 6) (Fig. 3B), and remarkably diminished in the other (no. 20) from $15.7 \%$ increase with the patent anterior cerebral artery to only $6.4 \%$ when the anterior cerebral artery was occluded. Systemic blood pressure remained constant before and after the $A_{1}$ occlusion, and the reduction in the ipsilateral carotid flow caused by $\mathrm{C}_{2}$ occlusion was approximately the same for each monkey. Following release of occlusion at $\mathrm{C}_{2}$ of monkey no. 6 , a slight reactive hyperaemia was observed in the ipsilateral carotid flow. This amounted to $7 \cdot 7 \%$ and lasted for about 40 seconds (Fig. 3B). There was no reactive hyperaemia in monkey no. 20.

INFLUENCE OF OCCLUSION OF THE POSTERIOR COM을 MUNICATING ARTERY ON $\mathrm{C}_{2}$ OCCLUSION The effect of $\mathrm{C}_{2}$ occlusion was examined in one monkey (no. 17) 0 을 after the ipsilateral posterior communicating artery had been occluded. The compensatory increase in $\frac{D}{0}$ the ipsilateral vertebral flow decreased remarkablys from $26.1 \%$ on the occasion of $\mathrm{C}_{2}$ occlusion with the $\overrightarrow{8}$ patent posterior communicating artery to $10.5 \%$ o with the occluded posterior communicating artery. Flow in the contralateral carotid showed an increase of $33.5 \%$, which was higher than the $24.8 \%$ increase produced by $\mathrm{C}_{2}$ occlusion when the posterior communicating artery was patent. An example is illustrated in Figure 10B.

INFLUENCE OF OCCLUSION AT $A_{1}$ ON $C_{1}$ OCCLUSION The anterior cerebral artery was occluded at $A_{1}$ before $C_{1}$ occlusion in two animals (nos. 6 and 17). Under such circumstances, the compensatory increase in flow of the contralateral internal carotid following $C_{1}$ occlusion was now completely abolished in both animals. When the $C_{1}$ occlusion was released there followed a reactive hyperaemia in flow of the ipsilateral carotid artery. This hyperaemia was $33.3 \%$ in no. 6 and $12.5 \%$ in no. 17 at its maximum and lasted for about one and a half minutes in both. Figure 11B illustrates this. In monkey no. 15, in which the anterior cerebral artery was congenitally absent on the left side, brief hyperaemia was observed in the right internal carotid flow after release of the right $C_{1}$ occlusion (Fig. 4). 


\section{A. OCCLUSION FOR 15 SEC.}
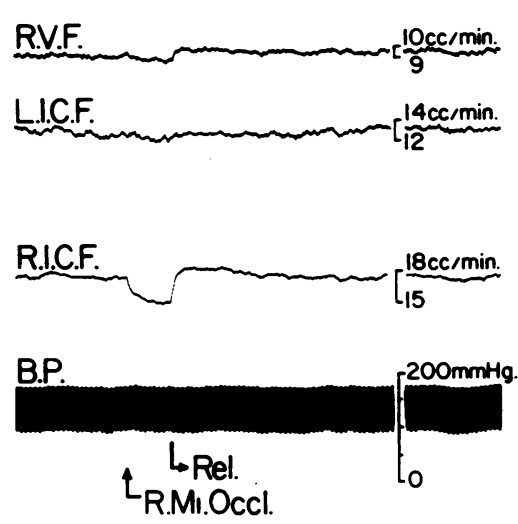

$\mathrm{Al} . \mathrm{CO}_{2}$

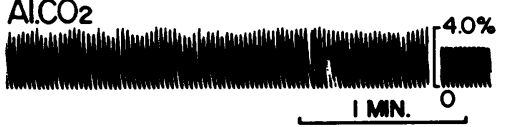

B. OCCLUSION FOR I MIN.
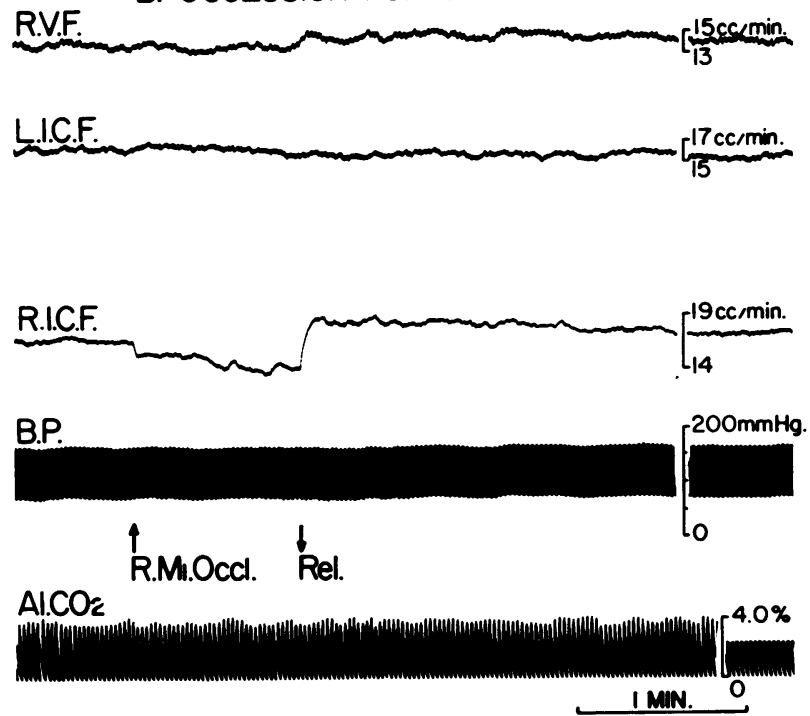

\section{OCCLUSION FOR 3 MIN.}
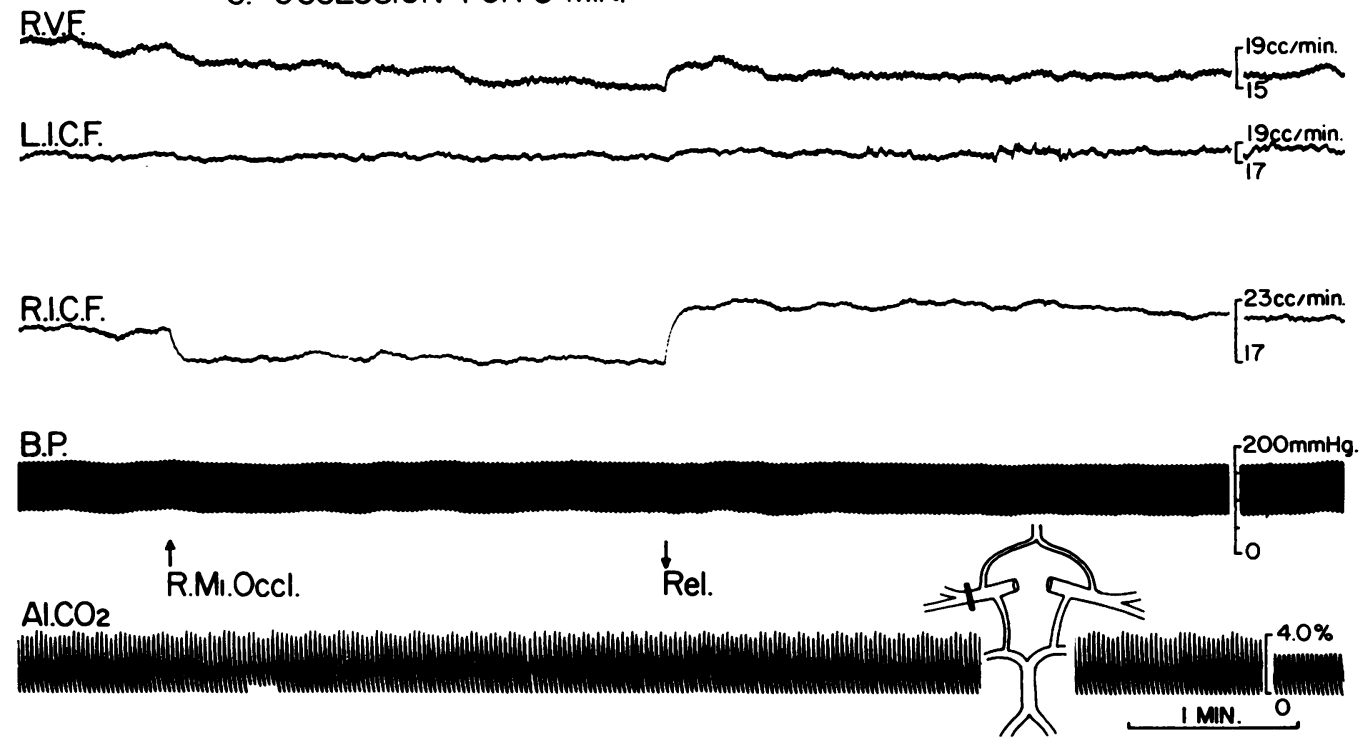

FIG. 9. Effect of right $M_{1}$ occlusion of various durations on flow in the right vertebral and the left and right internal carotid arteries (no. 17).

A Occlusion for 15 seconds.

$B$ Occlusion for 1 minute.

C Occlusion for 3 minutes.

The longer the period of occlusion, the larger and longer the reactive hyperaemia. 
A. R.POST.COMM.ART.PATENT
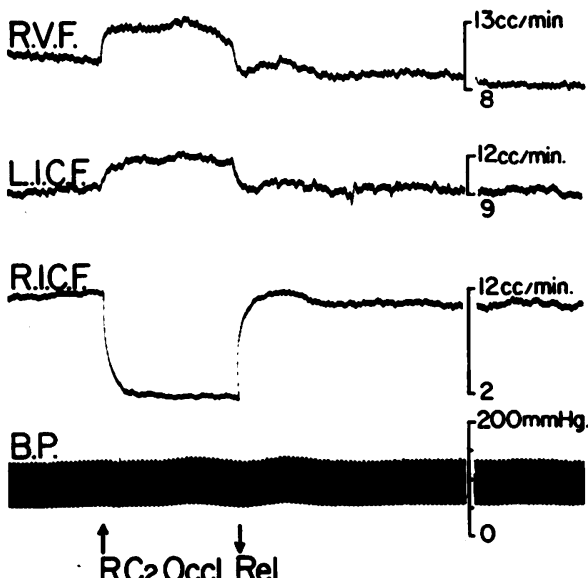

$\mathrm{Al.CO}$

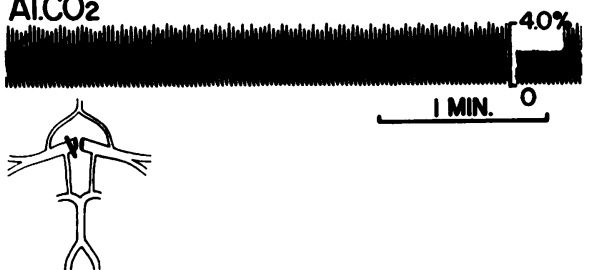

B. R.POST.COMM.ART.OCCLUDED
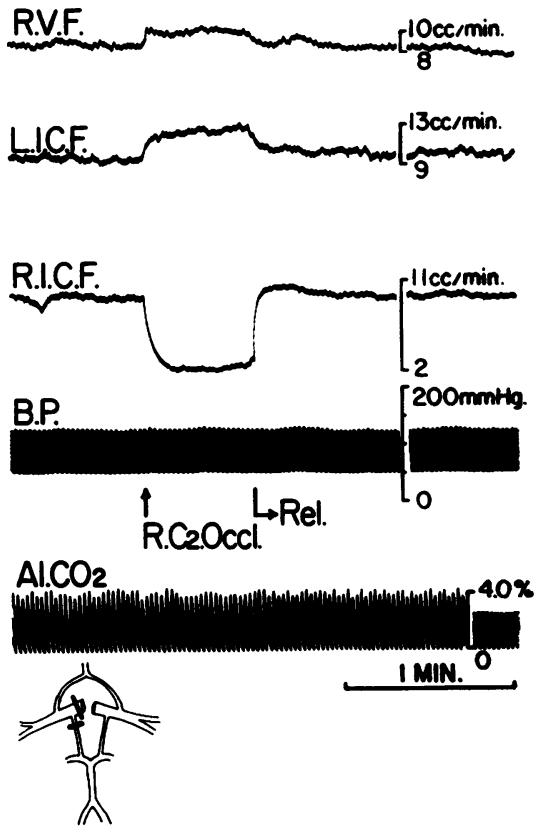

1 MNA.

Fig. 10. Records $A$ and $B$ are from the same animal (no. 17).

FIG. 10. Records $A$ and $B$ are from the same animal (no. 17).
$A$ Effect of right $C_{2}$ occlusion on flow in the right vertebral and the left and right internal carotid arteries.
$B$ The right posterior communicating artery has been occluded. $A$ magnitude of compensatory increase in right vertebr践 flow was reduced remarkably but not abolished completely.

\section{A. R.ANT.CEREB.ART.PATENT}

R.V.F.
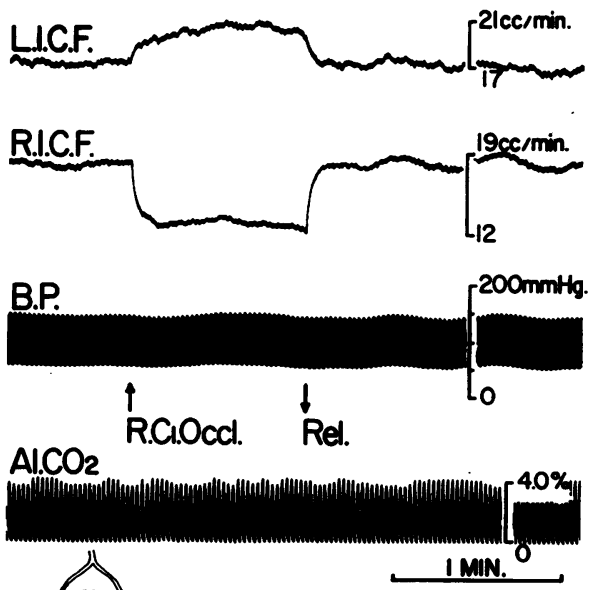

B. R.ANT.CEREB.ART.OCCLUDED
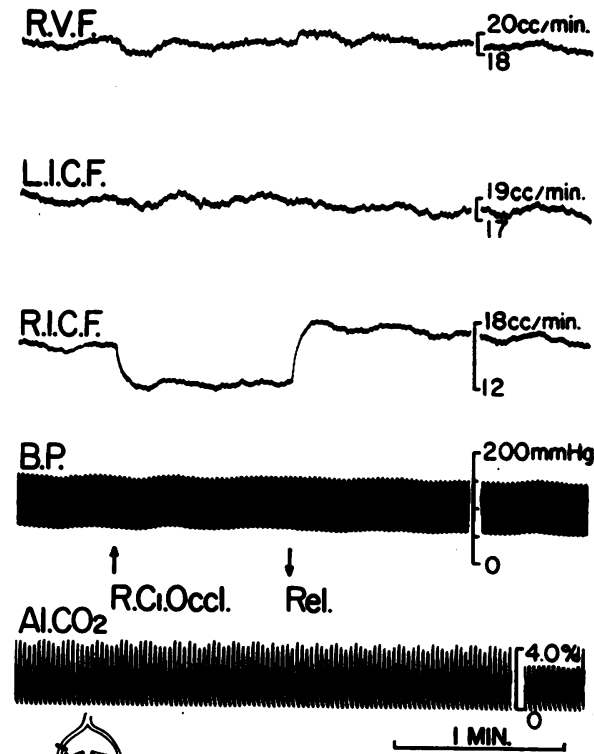

FIG. 11. Records $A$ and $B$ are from the same monkey (no. 17).

$A$ Effect of right $C_{1}$ occlusion on flow in the right vertebral and the left and right internal carotid arteries.

$B$ The right anterior cerebral artery has been occluded previously. A compensatory increase in left internal carotid flow $\Phi$ was nearly abolished thereby, and reactive hyperaemia is observed in right internal carotid flow on release of $C_{1}$ occlusion.? 
INFLUENCE OF OCCLUSION AT $A_{1}$ ON $M_{1}$ OCCLUSION In three monkeys (nos. 6, 9, and 11), the ipsilateral anterior cerebral artery $\left(A_{1}\right)$ was occluded before $M_{1}$ occlusion. After the ipsilateral anterior cerebral artery had been occluded, occlusion at $\mathbf{M}_{1}$ produced an increase in flow of the contralateral carotid instead of a decrease. The magnitude of increase was $0.1 \%$ in no. $6,7.5 \%$ in no. 11 , and $4.8 \%$ in no. 19 . Figure 7B illustrates an example of this change observed in monkey no. 11. As shown in this figure contralateral internal carotid flow increased rather gradually, and on release, it returned rather slowly to the pre-occlusion level without showing a period of overshoot. The reactive hyperaemia in the ipsilateral carotid flow was made more remarkable when the anterior cerebral artery was occluded before $M_{1}$ occlusion and release. For example, in Fig. 7A, the overswing was $16.7 \%$ and lasted for one minute, and in Fig. 7B, 30.0\% and continued for one and a half minutes.

\section{COMMENT}

Following $\mathrm{C}_{2}$ occlusion, ipsilateral carotid flow was reduced to 28.5 to $58.9 \%$ of pre-occlusion values with an average of $44.2 \%$. We believe that the remaining flow of the carotid artery becomes distributed to extracerebral tissues. In one monkey (no. 11), after the flow measurements had been made, the internal carotid was again occluded at $C_{2}$ with a silver clip, and dye was injected into the ipsilateral internal carotid artery in the neck. On that side, the dura mater, periosteum and bones of the anterior and the middle cranial fossae, the eye and other orbital contents as well as the periorbital facial soft tissues were heavily stained. It is, of course, well known in man and monkey that the internal carotid artery gives rise to the ophthalmic artery and other small branches at the base of the skull before piercing the dura mater, and these vessels anastomose with the branches of the external carotid artery (Krayenbühl and Yasargil, 1958; Gillilan, 1962).

In the present study, the external carotid artery was ligated on both sides and many of its small branches were also ligated to provide exposure of a considerable length of the arterial segment. It seems probable, as a result, that peripheral resistance in the extracerebral distribution of the internal carotid was reduced, due to a change in pressure gradient and possibly due to the vasodilatation produced by accumulation of carbon dioxide and other acid metabolites. Consequently, the contribution of the internal carotid to the extracerebral circulation probably was greatly increased. Moreover, $\mathrm{C}_{2}$ occlusion would increase the head of pres- sure in the internal carotid proximal to $\mathrm{C}_{2}$ and further increase the flow from the internal carotid into the extracerebral vessels listed above. For these reasons, the actual contribution of the internal carotid flow to the cerebral circulation cannot be calculated with accuracy from these measurements.

The collateral increase in flow of the contralateral carotid following $\mathrm{C}_{2}$ occlusion was completely abolished or markedly diminished by occlusion of the ipsilateral anterior cerebral artery before $C_{2}$ occlusion. Also in monkey no. 15, in which the contralateral anterior cerebral artery was absent, the compensatory rise was only $4.3 \%$. These facts strongly support the view that the anterior cerebral arteries provide the predominant course for collateral blood flow from the contralateral carotid following $\mathrm{C}_{2}$ occlusion. In brief, when $\mathrm{C}_{2}$ is occluded, the common pericallosal artery is supplied exclusively from the contralateral internal carotid artery, and by this means blood enters the middle cerebral territory (on the occluded side) through the ipsilateral anterior cerebral artery, depending on the intraluminal pressure differential between them (Rogers, 1947; Avman and Bering, 1961; Symon et al., 1963b).

The leptomeningeal collateral circulation between the anterior cerebral and the middle cerebral arteries on the occluded side provides a supplementary course for the compensatory increase in contralateral carotid flow (Vander Eecken, 1959). This latter route is proven by the compensatory rise in flow of the contralateral carotid observed in monkey no. 20 despite occlusion of the ipsilateral anterior cerebral artery. The progressive increase in contralateral carotid flow during the interval of $\mathbf{C}_{2}$ occlusion in monkey no. 11 is probably due to this contribution from the leptomeningeal collateral circulation. Symon et al. (1963b) have shown in a previous study that there is often a slight rise in flow in the smaller anterior cerebral branches abutting on the middle cerebral field, occurring within the first 15 seconds after occlusion of the ipsilateral carotid in the neck, but very little change was observed in flow of the larger vessels.

The ipsilateral posterior communicating artery provides the most important collateral route from the ipsilateral vertebral artery following $C_{2}$ occlusion, since occlusion of this vessel before $\mathrm{C}_{2}$ occlusion remarkably diminished the compensatory rise in flow of the ipsilateral vertebral artery. Furthermore, following occlusion at $\mathrm{C}_{2}$ the posterior cerebral arterial pressure is relatively higher than that of the carotid system distal to $C_{2}$ (Hardesty et al., 1960; Avman and Bering, 1961 ; Symon et al., 1963a). As a result of this pressure differential, the vertebrobasilar system diverts blood into the carotid field 
through the posterior communicating artery and the leptomeningeal collateral pathways. The moderate increase in flow in the ipsilateral vertebral after the posterior communicating artery has been occluded is due to the leptomeningeal collateral circulation between the vertebro-basilar and the carotid systems (Vander Eecken, 1959).

The mean decrease in ipsilateral carotid flow produced by $\mathrm{C}_{2}$ occlusion was significantly $(\mathrm{p}<0.01)$ greater than that following $C_{1}$ occlusion. After $C_{2}$ occlusion, the ipsilateral internal carotid artery is isolated from any direct contribution to the cerebral circulation, and the ipsilateral vertebral diverts blood into the territory of the internal carotid artery via the posterior communicating artery. However, occlusion at $C_{1}$ elevates the intravascular pressure at $C_{2}$ and produces a pressure gradient between $C_{2}$ and the posterior cerebral artery. Consequently, blood originally destined for the internal carotid now flows into the posterior cerebral artery via the posterior communicating artery.

Occlusion at $\mathrm{C}_{1}$ caused alteration in the haemodynamics of the ipsilateral vertebral artery. There was a decrease in four monkeys, it remained unchanged in three, and increased in only one of eight animals. If the blood flow from the internal carotid to the posterior cerebral artery was the same as the flow from the vertebro-basilar system into the carotid territory ihrough the leptomeningeal collateral pathways, the total vertebral flow remained unchanged. When the capacity of the leptomeningeal collateral circulation was exceeded, the vertebral was reduced, and vice versa. In general, a reduction in flow of the ipsilateral vertebral artery was produced by $C_{1}$ occlusion. There was a significant $(p<0.005)$ difference between the increase in flow of the ipsilateral vertebral following $C_{2}$ occlusion and the decrease after $\mathrm{C}_{1}$ occlusion.

McDonald and Potter (1951) have shown by dye injections that a 'dead point' usually exists at the posterior communicating artery, where blood from the carotid system and vertebral system meet and oppose each other without mixing. This dead point is, of course, a dynamic one, since the posterior communicating artery may function as an anteriorposterior and posterior-anterior anastomosis as requested. Such a dynamic function of the posterior communicating artery in man has also been shown repeatedly by means of arteriography. The present study adds quantitative data for these haemodynamic changes between the carotid and the vertebral arteries in the monkey.

The compensatory rise in contralateral carotid flow produced by $C_{1}$ occlusion may be explained in the same manner as for $\mathrm{C}_{2}$ occlusion. Both anterior cerebral arteries provide the predominant course of collateral flow. Complete abolition of the com- $\bar{z}$ pensatory rise in contralateral carotid flow can be achieved by occluding $A_{1}$ before occlusion at $C_{1}$; furthermore, the reactive hyperaemia is greater and $\stackrel{\text { ? }}{=}$ of longer duration. The mean increase in flow of the contralateral carotid was greater following $\mathrm{C}_{1}$ 品 occlusion $(23.6 \%)$ than following $\mathrm{C}_{2}$ occlusion $(19.7 \%)$, although the difference is not statistically significant. In $\mathrm{C}_{1}$ occlusion, the collateral flow from the vertebro-basilar system is made only via the leptomeningeal anastomoses, hence the contralateral $\underset{\vec{D}}{\vec{S}}$ carotid tends to provide a more efficient collateral $\bar{C}$ after $C_{1}$ occlusion than following $C_{2}$ occlusion.

Monkey no. 18 provided interesting data concurring the compensatory increase in contralateral $\stackrel{\mathbb{Q}}{\Omega}$ carotid flow after $C_{1}$ occlusion. In this animal, the

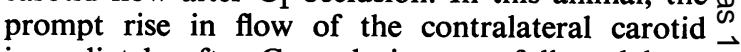
immediately after $C_{1}$ occlusion was followed by a $\vec{\circ}$ further gradual increase, which started within $15 \overrightarrow{\vec{H}}$ seconds of $\mathrm{C}_{1}$ occlusion and continued for 25 seconds $\stackrel{\omega}{\omega}$ until a maximum level was obtained. The gradual increase is probably due to an increase in leptomeningeal collateral circulation determined by an $\mathrm{N}_{\infty}$ accumulation of vasodilator metabolites (Meyer and i Gotoh, 1961; Symon et al., 1963a). The markef $\vec{N}$ increase in contralateral carotid flow $(72 \%$ of the pre-occlusion level) suggested that there we⿻日木 exceptionally well developed collateral pathways 通 this animal, which was confirmed during Mg occlusion.

Calculation of the volume flow of a single anteriof. $\overrightarrow{\mathscr{\phi}}$ cerebral artery cannot be made from the reduction of in flow of the ipsilateral carotid following $\overline{A_{1}}$ occlusion, because of the haemodynamic adjustments in flow through the posterior communicating and middle cerebral arteries. Following $\mathrm{A}_{1}$ occlusion, the common pericallosal artery is supplied exclusively $\stackrel{\square}{\mathbb{D}}$ from the contralateral carotid which results in an increased flow through the contralateral carotid. $\overline{\overrightarrow{0}}$ The decrease in ipsilateral veterbral flow is due to 3 blood flowing from the ipsilateral carotid via the ipsilateral posterior communicating artery because of the pressure gradient between the two.

For similar reasons, the contribution of the middle cerebral artery to cerebral blood flow cannot be calculated from the present data. However, the reduction in ipsilateral carotid flow following $\mathbf{M}_{1}$ ᄋ occlusion was significantly $(\mathrm{p}<0.005)$ less than that after $\mathrm{C}_{1}$ occlusion. Alterations in ipsilateral vertebral 응 flow after $M_{1}$ occlusion may be explained in the $D$ same way as those following $C_{1}$ occlusion.

Occlusion at $M_{1}$ produced a decrease in flow of the contralateral carotid in 11 monkeys out of 13 . $\Omega$ Following combined occlusion of ipsilateral anterior $N$ cerebral artery and $M_{1}$ occlusion in three monkeys, స్ట there was an increase in contralateral carotid flow 
instead of a decrease. These data are interpreted as follows: occlusion at $M_{1}$ increased the intraluminal pressure at $A_{1}$ on its own side and allowed the pressure gradient between $A_{1}$ and the common pericallosal artery so that it was now greater on the occluded side than on the contralateral side. Consequently, the common pericallosal artery became supplied predominantly by the anterior cerebral artery of the occluded side and the contralateral carotid flow became reduced.

These results suggest that the main contribution to the collateral circulation following $\mathbf{M}_{1}$ occlusion is via the ipsilateral anterior cerebral artery rather than the contralateral. The data do not agree with the result of a previous study (Symon, 1961) using radioactive isotopes, in which the main collateral was thought to be from the contralateral anterior cerebral artery. This discrepancy, however, is probably due to the absence of any recognizable spasm in the ipsilateral anterior cerebral artery following $M_{1}$ occlusion in the present experiment. Spasm in basal vessels in the monkey following mechanical stimulation has been reported by Harvey and Rasmussen (1951), Lende (1960), and Symon (1961). In the present study, slight spasm was observed in two animals. (After posterior communicating artery occlusion there was a spasm in the ipsilateral carotid lasting for one minute; in another there was carotid artery spasm continuing for approximately two minutes following $\mathrm{C}_{2}$ occlusion as shown in Figure 3A.)

Occlusion at $\mathrm{M}_{1}$ demands that the leptomeningeal circulation between the anterior cerebral territory and the middle cerebral field provide the collateral blood flow and this was clearly demonstrated by the compensatory rise in contralateral carotid flow following $M_{1}$ occlusion in the experiments in which the anterior cerebral artery had been previously occluded. If the increased flow of the ipsilateral anterior cerebral artery following $M_{1}$ occlusion was the same as the flow through the meningeal vessels, contralateral carotid flow remained unchanged. If the leptomeningeal collateral circulation was deficient, contralateral carotid flow was decreased, and vice versa.

The progressive increase of contralateral carotid flow over the period of $M_{1}$ occlusion observed in monkey no. 11 is best explained by a progressive accumulation of acid metabolites.

The unusual increase in contralateral carotid flow after $M_{1}$ occlusion and the absence of reactive hyperaemia after release in monkey no. 18 was due to exceptionally efficient leptomeningeal collateral pathways. Abolition of the compensatory increase in contralateral carotid flow and the appearance of reactive hyperaemia in the same animal under anaemically induced hypotension confirm the importance of maintaining a certain level of systemic blood pressure for the efficiency of the cerebral collateral circulation (Ralston, Rasmussen, and Kennedy, 1955; Denny-Brown and Meyer, 1957).

The reactive hyperaemia following release of the occluded middle cerebral artery increased in volume and duration depending on the length of the ischaemia. This fact supports the concept that the filling of an empty, low-resistance vascular bed (or pressure differential) is not the only mechanism responsible for reactive hyperaemia, but vasodilatation resulting from accumulated metabolites due to ischaemia probably plays an important role (Randall and Horvath, 1953).

\section{SUMMARY}

Alterations in blood flow through both internal carotid arteries and the ipsilateral vertebral artery following unilateral occlusion of an intracranial artery or arteries in the monkey have been recorded using three electromagnetic flowmeters applied to each artery.

The dynamic function of the circle of Willis and the leptomeningeal arterial anastomoses in forming a collateral circulation has been demonstrated, and its mechanism analysed.

The transistory overshoot (or hyperaemia) in blood flow of the internal carotid following release of an occluded middle cerebral artery supports the concept that cerebral vasodilatation was produced by accumulated metabolites resulting from preceding ischaemia and this plays an important role in cerebral reactive hyperaemia.

Hydrostatic mechanisms are not the only factors controlling the cerebral collateral circulation; metabolic factors also must be considered.

The importance of maintaining an optimal level of systemic blood pressure in order to maintain the cerebral collateral circulation has been confirmed.

This work is supported by grants from the United States Public Health Service, and from the Receiving Hospital Research Corporation.

Mr. Peter Miller provided valuable technical assistance.

\section{REFERENCES}

Avman, N., and Bering, E. A. (1961). A plastic model for the study of pressure changes in the circle of Willis and major cerebral arteries following arterial occlusion. J. Neurosurg., 18, 361-365.

Bakay, L., and Sweet, W. H. (1952). Cervical and intracranial intraarterial pressures with and without vascular occlusion. Surg. Gynec. Obstet., 95, 67-75.

Denny-Brown, D., and Meyer, J. S. (1957). The cerebral collateral circulation. 2. Production of cerebral infarction by ischemic anoxia and its reversibility in early stages. Neurology (Minneap.), 7, 567-579. 
Gillilan, L. A. (1962). In Correlative Anatomy of the Nervous System. Edited by E. C. Crosby, T. Humphrey and E. W. Lauer, p. 556. Macmillan, New York.

Handa, J., Ishikawa, S., Huber, P., and Meyer, J. S. (1965). Experimental production of the subclavian steal: Electromagnetic flow measurements in the monkey. Surgery, in the press.

Hardesty, W. H., Roberts, B., Toole, J. F., and Royster, H. P. (1960). Studies of carotid-artery blood flow in man. New Engl. J. Med., 263; 944-946.

Harvey, J., and Rasmussen, T. (1951). Occlusion of the middle cerebral artery. Arch. Neurol. Psychiat., 66, 20-29.

Kramer, S. P. (1912). On the function of the circle of Willis. J. exp. Med. 15, 348-364.

Krayenbühl. H., and Yasargil, G. (1958). Der cerebrale kollaterale Blutkreislauf im angiographischen Bild. Acta neurochir. (Wien), 6, 30-80.

Lende, R. A. (1960). Local spasm in cerebral arteries. J. Neurosurg., $17,90-103$.

McDonald, D. A., and Potter, J. M. (1951). The distribution of blood to the brain. J. Physiol. (Lond.), 114, 356-371.

Meyer, J. S., Fang, H. C., and Denny-Brown, D. (1954). Polarographic study of cerebral collateral circulation. Arch. Neurol. Psychiat. (Chic.), 72, 296-312.

- and Gotoh, F. (1961). Interaction of cerebral haemodynamics and metabolism. Neurology (Minneap.), 11, no. 4, pt 2, pp. 46-65.

_- Ishikawa, S., and Lee, T. K. (1964). Electromagnetic measurement of cerebral blood flow in the monkey. Effect of epilepsy and other procedures on jugular venous flow. J. Neurosurg., 21, 524-539.

Murray, K. D. (1964). Dimensions of the circle of Willis and dynamic studies using electrical analogy. Ibid., 21, 26-34.

Ralston, B., Rasmussen, T., and Kennedy, T. (1955). Occlusion of the middle cerebral artery under normotension, and anemically induced and chemically induced hypotension. Ibid., 12, 26-33.
Randall, J. E., and Horvath, S. M. (1953). Relationship between duration of ischemia and reactive hyperemia in a single vessel. Amer. J. Physiol., 172, 391-398.

Rogers, L. (1947). The function of the circulus arteriosus of Willis. Brain, 70, 171-178.

Rosegay, H., and Welch, K. (1954). Peripheral collateral circulation between cerebral arteries. A demonstration by angiography of $\vec{\theta}$ the meningeal arterial anastomoses. $J$. Neurosurg., 11, $\square$ 363-377.

Stern, W. E. L. (1962). A preliminary report of experimental and clinical observations upon cervical carotid artery blood flow. J. Neurol. Neurosurg. Psychiat., 25, 303-314.

Symon, L. (1961). Studies of leptomeningeal collateral circulation in Macacus Rhesus. J. Physiol. (Lond.), 159, 68-86.

-, Ishikawa, S., Lavy, S., and Meyer, J. S. (1963a). Quantitative $\overrightarrow{\vec{F}}$ measurement of cephalic blood flow in the monkey. A study of $\mathscr{P}$ vascular occlusion in the neck using electromagnetic flowmeters. J. Neurosurg., 20, 199-218.

,-- , and Meyer, J. S. (1963b). Cerebral arterial pressure changes and development of leptomeningeal collateral circula - $\bar{\sigma}$ tion. Neurology (Minneap.), 13, 237-250.

Tönnis, W., and Schiefer, W. (1959). Zirkulationsstörungen des Gehirns im Serienangiogramm. Springer, Berlin.

Vander Eecken, H. M. (1959). The Anastomoses between the की Leptomeningeal Arteries of the Brain. Thomas, Springfield, $\overrightarrow{0}$ Illinois.

Welch, K. Stephens, J., Huber, W., and Ingersoll, C. (1955). The collateral circulation following middle cerebral branch oc- $\vec{\omega}$ clusion. J. Neurosurg., 12, 361-368.

Woodhall, B., Odom, G. L., Bloor, B. M., and Golden, J. (1952) Direct measurement of intravascular pressure in components of the circle of Willis. A contribution to the surgery of congenital cerebral aneurysms and vascular anomalies of the $N$ brain. Ann. Surg., 135, $911-922$. 